\section{Michael Walker Ramage}

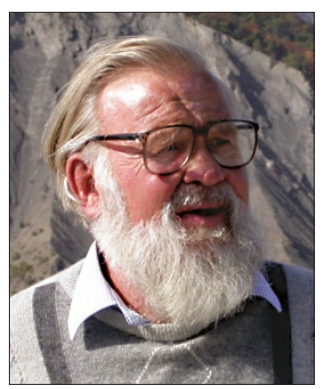

Michael will be remembered as one of Scotland's most distinguished and most respected dental practitioners. He qualified from the University of Edinburgh in 1959 with the Gold Medal and, after house jobs at 'The Royal' there, won a prestigious Fulbright Scholarship which gave him the opportunity to spend a year at the highly esteemed North Western University Dental School in Chicago. So highly were his skills regarded there, that they tried to persuade him to stay on the Faculty. Michael demurred in order to take one of his - subsequently perennial - 'journeys on a shoe-string', discovering other countries and cultures.

We first met Michael as primary FDS students, living together at Nuffield College in Lincoln's Inn Fields in 1963. We remained lifelong friends and regard ourselves especially fortunate in that we met at an age where such friendships generate a depth of the utmost quality. As our professional careers diverged, we regularly came together to compare notes, prejudices and ambitions.

His own career was notable for the exceptional quality of his clinical work, the loyalty and honesty with which he related to his patients, and the rightful respect in which he was held, as was amply demonstrated by their presence at his funeral service in Edinburgh on 11 July 2005.

In addition to his professional skills, Michael's interests were both far-reaching and highly informed. He had a detailed knowledge of matters ranging from the history of ocean liners and air-

\section{Alwin 'Tim’ Perkins}

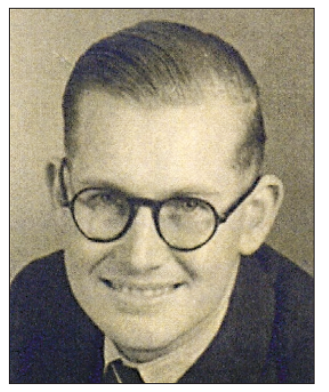

Dr Alwin Perkins, known as Tim, died on 29 October 2005. A dental practitioner in Northampton, he was respected locally for opening his practice early in the morning so that boot and shoe factory workers could attend, something practically unheard of at the time. He was the first dentist in the town to have a purpose-built practice, in the Harlestone Road, which he designed himself.

Dr Perkins was born in January 1919 into a family of acclaimed engineers and lived most of his life in Northampton, except during World War Two when he was based at the Royal Air Force Dental Department in Kirkham. He trained at the Royal Dental Hospital in London and the Edinburgh Royal Infirmary and was a Fellow of the Royal College of Surgeons. Dedicated to his profession, he won first prizes in dental prosthetics, metallic work,

\section{He was a credit to our profession and we are fortunate to have been his friends.}

craft to ornithology and horticulture. As a young man, he competed in Scottish golf championships and was a lifelong member of Muirfield.

Michael was an acute observer of human nature, outwardly expressed by his outstanding photographic skills - certainly technically, but especially artistically. These skills were admired and acknowledged professionally and deeply appreciated by his many friends and acquaintances. Organising this material from the charmingly distrait state in which it existed was a task he looked forward to with relish once his travelling days were over.

His retirement from active practice a few years ago led to renewed peregrinations, including two extensive scientific survey trips to the Antarctic. His brave final trip was a return to Cambodia, Thailand and Vietnam.

During his difficult last weeks in the Western Infirmary in Edinburgh, Michael's customary warm good humour remained unchanged. The memory of his smile at the pleasure of a visit from us is something we will always cherish.

He was a credit to our profession and we are fortunate to have been his friends.

Newell Johnson, Peta Smith and Peter Stäheli Queensland, Argyll and Dorset

\section{Dedicated to his profession, he was respected locally for opening his practice early so that factory workers could attend.}

anaesthetics, histology, dental disease in children and radiology. Tim was also a well-known member of his parish, carving a crucifix that hangs on the west gallery wall of St Gregory's church and the stone altar for the original church of St Patrick's in Duston. Despite his many achievements he was known as a very humble and quiet man, skilled and knowledgeable in wood carving, masonry, painting and making musical instruments, furniture and clocks. Dr Perkins is survived by his wife, two sons and three daughters and will be much missed.

\footnotetext{
Death notice

Sydney George le Strange Beaton BDS [London] died on 14 January 2006. Born on 4 February 1922, Sydney qualified at Guy's Dental School in 1944. After service in the army during the latter stages of the war, he took over and continued his father's dental practice in Heston, West London. He was an active member of the British Dental Association and a keen supporter of the Benevolent Fund for over 40 years.
} 